\title{
The Institutional Structure of Society and the Economic Environment as Factors of Quality Assurance of Competitive Products
}

\author{
Elena Blagireva \\ Russian State Specialized Arts Academy \\ Moscow, Russia
}

\begin{abstract}
The article examines the main elements of the institutional mechanism of competitiveness. Substantiates the relationship and interdependence of competitiveness with the institutional aspects of the development of economic activities, and the impact of institutional environment on the competitiveness of goods and services in the Russian Federation.
\end{abstract}

Keywords-institutional framework; competitive products; competitive risks; institutional mechanism of competitiveness

\section{INTRODUCTION}

In the work on providing the competitiveness of the product an important place is given to the institutional structure of the society, which determines a number of limitations, acting as a filtering mechanism, providing selection of the rational and irrational solutions.

At the same time it is important to consider that abnormal information spread among the participants of the market leads to an asymmetry. Lack of complete information access brings contradictions among the opportunity to completely control a particular mass of information on one hand; on the other hand to have an equal approach to information of all subjects in accordance with the market principles. In conditions of the dominance of imperfect competitiveness there is a chance of misuse of information asymmetry, which leads, as a rule, to an increase of transaction costs.

Information incompleteness is one of the reasons of the market uncertainty, which means that economical subjects should take their decisions in unpredictable conditions, which can hardly be estimated.

At the same time economic uncertainty increases not only with the society's technological modernization: the environment and work conditions are even more uncertain and changeable. Resources' and actives` prices, currency exchange rates, interest rates, stocks` and shares`rates vary in a much more broad limits. This can be visibly seen especially at current time, when the Russian Federation found itself practically isolated from the Western world. In these conditions an important conversation about the competitiveness of the Russian goods, services and the whole economy sectors has been discussed at a session of the State Council of the Russian Federation in September 2014.

The President of the Russian Federation Vladimir Putin suggested considering the present economical situation as a chance of a fast economic diversification. In particular, it was said that there's no need to export natural resources, but the product of its` processing. A stake on the development of the real economy sector was named the main resource of the growth, especially considering the fact that the trust to the locally-made products has greatly increased in Russia. Today the state should help business to use this situation as another resource of an economy growth.

Vladimir Putin said: «Our main objective is to use one of the Russian main competitiveness advantages, which is an immense internal market. Our aim is to fill it with competitive high-quality goods, produced by the real sector of the domestic economy, keeping stability and the balance of the economy in general. We are talking about the formation of such an economy policy, in which all the efforts of the federal and the regional power bodies should be reoriented towards the development of the real economy sector. In the following year or two a real breakthrough should be made in the increase of the Russian real economy sector; we have to make something that would take years in the previous time».

It isn't easy to be made, considering the fact that a principle of the equal access of all countries to different markets and services is broken. A principle of just and free competition and the maximum benefit in trade is ignored.

At the same time it should be considered that competition depends on institutional organization of the society, which determines the completeness of social mechanisms of interaction at the maximization of the benefit of the rational choice in production and the spread of the benefits. Competition at present represents a fight with the rules, limitations in the frame of economic and political competition.

Yet, current situation stimulates an investment increase into the Research and Development, innovation usage, product quality increase work and leads towards decrease of losses. Complete information and transparency lack both in 
internal and external markets leads to competition increase. Different institutional systems have different innovation opportunities. Regions lagging behind lose their innovation potential, since institutional environment doesn't provide a necessary confidence among the businessmen.

A number of competition also depends on the development of institutional environment, which includes the norms and regulations of working life, determining the behavior of the market participants as well as the active mechanisms. For example, N. Tarnavskaya marks the following signs of competition: chaotic nature, dynamics, aggressiveness, unpredictability. It allows us to speak about an importance of rejection of the company-centered approach in the conditions of the creation of a creative network as a competition subject. [7, p.16]

In the conditions of institutional uncertainty there's a problem of an optimal institutional framing of the system of work. Lack of institutional structure of competition is shown in the slowness of the formation of the market mentality type and the population behavior.

Implementation of a number of old-fashioned kinds of institutions, formal and informal rules and sometimes their lack in conditions of information asymmetry marks the functioning of ineffective innovation mechanism.

Lack of a number of formal institutions, norms and regulations, behavior norms and old rules prevents institutions` regular work.

At present time there's an acute necessity of research to determine and ground an effective institutional policy, providing competitiveness of the domestic goods and services. At the same time it is important to find a direct connection between the competitiveness and the quality categories.

As a kind of guess we suggest an idea that the theoretic formalization of competitiveness in connection with the processes of institutionalization allows to make a forecast of a possible vector of the development of economic relationship in Russia.

In modern conditions of competitive environment, direct interaction of the Russian and the Western producers, competitiveness of goods and services becomes a strategic resource of the development of the Russian economy.

In the Letter of the President of the Russian Federation Vladimir Putin to the Federal Council of the Russian Federation in 2014 it is stressed that competitiveness increase of the Russian economy becomes one of the priorities of the country's development.

Low competitiveness of the Russian product on the major criteria such as the quality, assortment and price became the main reason of the pushing of the domestic product away from the Russian market. Better quality product of a better price makes responsive measures from the competitors` side more difficult. Quality improvement takes a long cycle, which begins with gaining of the economic and scientific information.
Modern producers, which do not pay necessary attention to the quality issues become bankrupts. An idea of quality in modern conditions is determined by the demand of the consumer, which becomes more and more picky. That is why the quality is a competitiveness indicator is an important factor of steady growth of the Russian economy and its integration into the world community. [6]

Thus, there's a need of a new consideration of the competitiveness problem in the modern reality.

In the recent past Russian economy was based upon general state and direct planning. It meant that all decisions were taken centrally about the quality of the product, resource usage, labour and capital usage and salaries. Central economic institutions developed work plans, directives were given, which were later informed to the ministries, enterprises, factories and even to workers.

At present time competitiveness of the national economy on the basis of institutional factors is one of the factors of the quality and quantity reformation of social and economic spheres, which leads to the improvement of social life level. Meanwhile modernization of economic sphere and investment climate improvement are the main instruments to gain this objective. At the same time a kind of property, which became an absolutely technical category, does not make any influence on the product quality. The main factors are the market structure, competition level, while property rights should be spread between the participants of the process in order to maximize the profit.

The result of the mass institutional changes has become cutting of the state presence in the economy and business activity concentration in private sector.

Yet, it does not mean that all the problems have been solved. In Russia there bodies. It leads to the creation of «shadow payments» to the controlling bodies, multiple coordinations with the executive power on the regional and local levels. are a lot of administrative barriers, in particular, duplication of controlling.

In the author's opinion, it would be wiser to make a list of the state controlling bodies, defining the functions, rights and responsibilities of each organization, in order to prevent duplication.

It happens in spite of the fact that the state plays a role of an arbitre in economic liaisons, based on the Law and the Russian Federation determines the rules, regulating relationships between enterprises, resource providers and consumers. At the same time, in the author's opinion, the level of the state regulation of the economy should depend on the real market situation and the necessity of the state in a particular stage of the market relationship.

Head of the Government of the Russian Federation Dmitri Medvedev has justly mentioned: «The issue is not only in the legislation perfection, but also in its correct implementation. It is an issue of the definite practice of the law».

It is necessary to regulate the checking activity in order to prevent the usage of the controlling and observation 
mechanisms as a way to suppress the enterprises as well as to fulfill free control and observation procedure implementation. In July 2015 the Head of the Russian State signed a law, liberating small business of checking for the period from 01.01.2016 to 31.12 .2018 . It is prohibited to the bodies of power to make planned checking of the small business. The law calls such checking «rude law breaking» and the results of such checking are believed to be illegal.

At the same time together with the state bodies of quality and safety control of the product institutional bodies play a greater role in modern economy. Federal services, committees, inspections, ecology and sanitary services, nuclear energy, labour safety bodies are given special functions on control and supervision. In the author's opinion, clear formulation and fixation in the norms and acts the state economy policy are the necessary conditions of the effective usage of the means and methods of the economy's state regulation. Only with this condition Russian economy can be moved to the competitive rail.

\section{PRINCIPLES OF FORMATION OF INSTITUTIONAL COMPETITIVENESS}

In the process of competitive fight as a main principle of institutional competitiveness of the national economy, in the author's opinion and according to the literature analysis the following factors should be determined: complexity, competitive positions and opportunities`accessibility, selfdiscipline, succession, etc.

At the same time an institutional competitiveness may be considered from two positions: from the level of the development and economy modernization and in comparison with the competitive advantages of the other subjects.

It is important to stress that the national economy's competitiveness is concluded in the protection of its market share in the world market and its ability to compete depends on its major attributes, defining the attractiveness of the whole territory of the country as a place of the placement of institutions and participants as well as from both strong and weak economic agents.

The main components of the institutional competitiveness of the national economy are:

- subject institutions;

- object institutions;

- institutional environment;

- institutional mechanism of competitiveness (competitive positions) [5]

National economy competitiveness increase covers the system of institutional interests of working subjects of all levels, leading to the creation of absolutely new economic interests as well as a deeper understanding and perfection of the existing ones.

The state may help the creation of effective market institutions as well as create institutional structure, which does not allow to show the advantages of the competitive order because of the monopoly of power and other factors, leading to transaction losses growth. It all depends on particular historic conditions and comparative effectiveness of the work coordination. And although the state becomes a necessary factor of the progressive working systems, its institutions may not only provide an effectiveness increase (in the meaning of Pareto conditions achievement of the optimal resource spread), but also prevent it. [4]

In the author's opinion [2], there are two clear approaches towards the analysis of the state policy in the frame of institutional and research programs: an exogenous and an endogenous ones.

According to an exogenous approach to the research of the state economic policy, the main attention is given to the positive (and easily observed) external balance between particular measures and the happening economic processes. The connection between the instruments and results of the policy is strictly casual. Such an approach does not mean any particular analysis of the internal mechanisms of the system functioning or its any changing.

According to the endogenous approach the main accent is made on the change as a result of the measures of the state economy policy and the mechanisms of interaction of the systems subjects, on which an impact of the system is directed. Thus, the success of the implemented economic instruments depends on the coordination of the vectors of the economic policy and the internal (institutional) changes in the society, generated in the process of work.

It should be mentioned that an institutional structure of any economy is first of all the result of activity of its government and spontaneous evolution choice of the most effective institutions. Western countries with market economy possess a developed institutional structure, correspondent to the predominant way of economic coordination. That is why such countries may allow themselves to use the means of direct and indirect state involvement in order to implement a wishful economic policy without a considerable damage to the national wealth.

Quite a different situation is observed in the countries with undeveloped market relationship or with a transitional economics where the market relationship are still being formed or just absent. The effectiveness of such economies is radically lower than the developed market or even the centrally managed system. And if the state in the period of transitional economy economic relationship is regulated too much, then it has a negative effect upon the rhythm and quality of formation of particular market institutions.

As a result, according to the author, it may be concluded that an institutional structure is a particular systematized number of institutions, creating the forms of economic behavior, limiting the working subjects, which are formed in the frame of a particular system of work.

All the above mentioned means that not every measure of the state policy of the developed countries may be used in the conditions of transition economy. The state policy first of all should be directed to the creation of the conditions for the 
institutes`creation and, logically, an effective institutional structure at any stage of economic development.

Market economy cannot exist in the institutional vacuum. That is why a shortage of the market regulation as a coordination mechanism will be necessary changed by some, not necessarily effective, mechanisms. At the same time, lack of the mechanism of market regulation may be compensated by the direct measures of administrative control from the powerful state, otherwise the market moves to the shadow and regulates itself by the traditional norms, typical for the patrimony society.

Russian Economic Development Minister Alexey Ulyukaev mentioned at the session of the State Council that special measures of competitiveness providing should be concentrated first of all on the oil and gas industry, chemistry, oil chemistry, military and defense complex and financial and banking industries. «Here we should be not a defensive, but an attacking part — and I mean not only import substitution, but also obtaining noble positions in the world market and world chains of additional value», Mr. Ulyukaev said.

At the same time, according to the minister, Russia should stimulate non-resource export. In his words, not less than $6 \%$ of annual growth are necessary. At the same time the government will subsidize an interest rate of the export credit. I the following three years 10 bln rubles will be directed to these objectives.

This disbalance, which have been formed in the Russian economy in general and in particular are not the result of the general state activity, but a result of an activity of social groups (social interests groups), which benefit from such disbalance and whose position determinate both new formal rules and informal practices formalization.

In order to perfect the mechanism of competitiveness of the national economy in general the development of the instruments of the quality appraisal and the results of complex analysis of the basic directions of social and economical, political, institutional and managerial activities are necessary. [5]

All this will help to specify basic competitive positions of the country in general and in particular. At the same time at present there's a need to reconsider competitiveness problems in modern reality. [3]

In modern conditions the basis of competition is determined not by the price factors, among which quality is the main priority among the competitiveness' index. Provision to the market of a better quality or a new consumer price makes repulsive measures from the competitors more difficult, since the quality formation takes a longer time, beginning with accumulation of economic and scientific and technical information [1]

Competitiveness' economics evolutionizes into the competitiveness of life quality, which is a combination of physical, intellectual, moral and social benefit of particular social groups in achievement of an acceptable life level.
According to the author, the problem of competition increase of domestic product should become a national idea in the country. For the sake of it concentration of every enterprise's effort is necessary as well as state managerial bodies and the administration of the subjects of the Russian Federation as well as scientific institutions, higher and comprehensive schools, mass media and ordinary customers. In this meaning, in the author's opinion, a particular propaganda of the Russian goods` and services` as easier and more reliable production is necessary.

Besides realization of the very necessity of competitiveness increase it is necessary to prove the whole world that Russia as a country may be competitive. Domestic production competitive opportunities`increase is a major and complex objective, meant to increase investment and innovation activity, regulating external economic activity, aimed for protection of modernized industries and stimulation of the export of the competitive production.

An influence of the institutional environment to the competitiveness of the product can not be estimated. In particular, one can not estimate corporate economic relationship impact on the increase of the competitiveness of the product.

But yet, upkeeping of the competitive environment is in the area of institutional projecting, where the state activity is necessary. It is important to say that among economic regulators there are no perfect ones, which proves in its turn the necessity of some correction.

The state should actively interact with the market, but by no means should interfere into the natural mechanisms. At the same time there should be different interim mechanisms, helping to solve the problem of the product quality increase. Such work should be considered effective.

Non-government organization World Economic Forum offered a rating of global competitiveness for 2014-2015. In spite of a complex Geo-political situation and economic difficulties Russia has improved many positions. The country has occupied 53rd place of 144 on the global competitiveness index, having moved 11 positions ahead. This index determines the life level based upon 113 factors, divided into 12 groups, including: infrastructure, institutions quality, health and primary education, macro-economic stability, professional skills, financial market and development and the effectiveness of the goods` and services market, labour market effectiveness, internal market value, companies`competitiveness and innovation potential. At the same time Russia's best internal market value is its internal market. It is on the 7th place. Also, there is quite a good position in the macro-economic segment. It is on the 31 st place.

\section{CONCLUSION}

The government should actively interact with the market, without replacing their interference with natural market mechanisms. Along with this must exist and various intermediate institutions that help solve the problem of improving the quality of the product. 


\section{REFERENCES}

[1] Andreeva T.A. (2014) Integration of quality management into the strategic management of the organization. Bulletin of the Saratov State Socio-Economic University, no. 2, pp. 29-34.

[2] Belokrylova O.S., Volchik V.V., Muradov A A. (2010) Institutional features of income distribution in transition economies.

[3] Versan V.G. (2014) Quality and growth of the real sector of economy. Business excellence, no. 3, pp. 34-37.

[4] Gloveli G.D. (2011) History of economic theory.

[5] Lukanin Yu. V. (2012) Structural aspects of the institutional competitiveness of the national economy. Terra economicus, T. 10. Vol. 3, pp. 5-8.

[6] Mazur I.I. (2011) Quality Management: textbook for universities, p. 399.

[7] Tarnavskaya N. (2009) The latest manifestation of competition in a society that is based on the knowledge. Economy of Ukraine, no. 2, pp. 4-16. 